\title{
Serial third trimester ultrasound examinations in predicting fetal weight
}

\author{
Ardışık üçüncü trimester ultrason incelemeleri ile fetal ağırlığın tahmin edilmesi
}

\author{
Nilgün Güdücü, Gökçenur Gönenç, Herman İşçi, Alin Başgül Yiğiter, illkkan Dünder
}

\begin{abstract}
Objective: The aim of this study was to compare the accuracy of estimated fetal weights obtained by ultrasonographies performed at different weeks in the third trimester and just before delivery.

Methods: A total of 664 patients underwent three serial ultrasonographic examinations in the third trimester. The sonographically estimated fetal weight was calculated using the Hadlock formula and then converted into percentiles. The estimated fetal weight percentiles were compared with the actual birth weight percentiles at delivery.
\end{abstract}

Results: Mean maternal age was $30 \pm 4$ years (18-42 years), mean gestational age at first ultrasound was $32 \pm 0.5$ weeks (30.4-33.6 weeks), mean gestational age at second ultrasound was $36 \pm 0.4$ weeks (35-36.9 weeks), mean gestational age at third ultrasound was $38.6 \pm 1$ weeks (36.3- 42 weeks). Mean gestational age at delivery was $39 \pm 1$ weeks (36-42 weeks), mean birth weight was $3422 \pm 423$ grams (1900-4900 grams). Correlation coefficients of estimated fetal weights percentiles at first, second and third ultrasounds were significantly correlated with birth weight percentiles $(r=0.556, p<0.001),(r=0.623$, $p<0.001),(r=0.747, p<0.001$, respectively).

Conclusion: Ultrasonographic fetal weight estimations correlate with the actual birth weight better when performed in the late third trimester, but ultrasonographic fetal weight estimation early in the third trimester may allow for better follow up and planning of delivery both in small and large for gestational age fetuses. J Clin Exp Invest 2013; 4 (1): 28-33

Key words: Fetal weight estimation, third trimester ultrasound, Hadlock formula

\section{INTRODUCTION}

Accurate prediction of birth weight is of paramount importance to reduce the chance of fetal morbidity and mortality. A fetus with growth restriction is at increased risk of hypoxia and perinatal death, on the other hand a macrosomic fetus is associated with an increased risk of cesarean section, fetal injury

\section{ÖZET}

Amaç: Bu çalışmanın amacı, üçüncü trimesterin değişik haftalarında ve doğumdan hemen önce yapılan ultrasonografik ölçümlerin tahmini fetal ağırlığı tespit etmedeki doğruluğunu belirlemektir.

Yöntemler: Toplam 664 hastanın üçüncü trimesterde yapıImış 3 adet ultrasonografik verisi elde edildi ve Hadlock formülü ile tahmini doğum ağırlığı ve persentili hesaplandı. Daha sonra tahmini fetal ağırlık persentilleri, doğumdaki gerçek ağırlık persentili ile karşılaştıııldı.

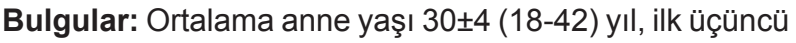
trimester ultrasonunun yapıldığı hafta ortalaması $32 \pm 0.5$ hafta (30.4-33.6 hafta), ikinci ultrasonun yapıldığı hafta ortalaması 36 \pm 0.4 hafta (35-36.9 hafta), üçüncü ultrasonun yapıldığı hafta ortalaması $38.6 \pm 1$ hafta (36.3- 42 hafta). Doğumun gerçekleştiği ortalama gebelik haftası $39 \pm 1$ hafta (36-42 hafta), ortalama doğum kilosu $3422 \pm 423$ gram (1900-4900 gram). Birinci, ikinci, üçüncü ultrason ölçümlerinde elde edilen persentillerin doğum ağırlığı persentili ile korelasyonu (sırasıyla, $r=0.556, p<0.001$ ), $(r=0.623, p<0.001),(r=0.747, p<0.001)$ istatistiksel olarak anlamlı bulundu.

Sonuç: Üçüncü trimesterin sonunda yapılan ultrasonografik ölçümler fetal ağırlığı daha iyi tahmin ettirir, ancak üçüncü trimesterin başında yapılan ultrasonografik ölçümlerin de fetal ağırlıkla korelasyonu iyidir ve gebelik yaşına göre küçük ve büyük bebeklerin yönetimi için daha avantajı olabilir.

Anahtar kelimeler: Tahmini doğum ağırlığı, üçüncü trimester ultrasonu, Hadlock

and maternal complications. ${ }^{1,2}$ For the prediction of birth weight some authors developed formula by using only maternal characteristics, ${ }^{3}$ some authors compared equations depending on ultrasound measurements ${ }^{4}$ and some others compared ultrasound measurements with clinical estimation ${ }^{5}$ or combined clinical and ultrasonographic parameters in an equation. ${ }^{6}$ 
Previously it was shown that ultrasonographic fetal weight estimations between 34 and 37 weeks of gestation allow for more accurate prediction of birth weight than sonograms obtained just before birth and at term. ${ }^{7}$ Others recommended ultrasonographic fetal weight estimation before delivery. ${ }^{8}$ The aim of our study was to investigate the accuracy of estimated fetal weights (EFW) obtained by ultrasonographies performed at different weeks in the third trimester and just before delivery. We used Hadlock's equations and assumed that the fetuses did not cross the growth percentiles from the day of the sonogram until delivery. ${ }^{9}$ To the best of our knowledge this is the first study that compared three serial ultrasonographic weight estimations in the third trimester.

\section{METHODS}

This was a retrospective study conducted by searching the data of pregnant women attending to our obstetrics policlinic between January 2006 and April 2011. In our clinic, routine ultrasonography was performed every month after 30 weeks of gestation. The study protocol was in line with the Declaration of Helsinki. All measurements were carried out by two obstetricians (NG, $\mathrm{HI}$ ) using the 5-megahertz $(\mathrm{MHz})$ curvilinear abdominal transducer, GE Electric Voluson 730 Expert. Gestational age was determined by the last menstrual period and only patients with a known first trimester crown-rump length (CRL) were included. Ultrasound documentations of the measurements of biparietal diameter (BPD), head circumference (HC), abdominal circumference $(A C)$ and femoral length (FL) were obtained. Exclusion criteria were pregnancies with incomplete information, known abnormal fetal karyotype, congenital malformations, multiple pregnancy, maternal illnesses as diabetes, hypertension, gastrointestinal malabsorption and also smoking. We did not exclude any case on the basis of abnormal fetal biometry or birth weight. We did not take the gender of the fetus, amniotic fluid volume and fetal presentation at the time of ultrasonography into consideration.

The study included 664 patients that underwent 1992 ultrasonographic measurements. Patients with serial fetal weight estimations between $30+1$ and $33+6$ weeks of gestation, between $35+1$ and $36+6$ weeks of gestation and then within 10 days before delivery were taken into consideration. EFW was calculated in all cases using the formula of Hadlock, which incorporates fetal BPD, HC, AC and $\mathrm{FL}^{10}$ and then converted into percentiles to compare with the birth weight percentiles, as this formula was shown to be the most consistent throughout the studies performed in the normal pregnant population. ${ }^{11}$ The EFW percentiles were compared with the actual birth weight percentiles at delivery. Small for gestational age (SGA) was defined as below and equal to the $10^{\text {th }}$ percentile for that gestational age and large for gestational age (LGA) was defined as above and equal to the 90th percentile for that gestational age.

\section{Statistical analysis}

For statistical analysis we used NCSS (Number Cruncher Statistical System) 2007 and PASS (Power Analysis and Sample Size) 2008 statistical Software (Utah, USA). Data showing anthropometric parameters were presented as mean plus minus standard deviation. Data showing normal distribution of parameters were compared with Paired samples t-test, data showing non-normal distribution of parameters were compared with Wilcoxon test. For categorical analysis, we used McNemar test, Odds Ratio and Pearson's correlation coefficient Within $95 \%$ confidence interval $p$ values $<0.05$ were considered as statistically significant. The results were considered statistically significant when the $p$-value was calculated less than 0.05 at a confidence interval of $95 \%$.

\section{RESULTS}

We included 664 patients in our study. The demographic features of the patients were shown in Table 1. Mean maternal age was $30 \pm 4$ years (18-42 years), mean maternal height was $164 \pm 5.8 \mathrm{~cm}(149$ $180 \mathrm{~cm})$, mean maternal weight before pregnancy was $62 \pm 10 \mathrm{~kg}(40-104 \mathrm{~kg})$, mean maternal weight at delivery was $78 \pm 10 \mathrm{~kg}(54-117 \mathrm{~kg})$, mean maternal weight gain during pregnancy was $16 \pm 5 \mathrm{~kg} \mathrm{(-2}$ to $+45 \mathrm{~kg}$ ), mean gestational age at first ultrasound was $32 \pm 0.5$ weeks (30.4-33.6 weeks), mean gestational age at second ultrasound was $36 \pm 0.4$ weeks (35-36.9 weeks), mean gestational age at third ultrasound was $38.6 \pm 1$ weeks (36.3-42 weeks), mean EFW at first ultrasound was $1954 \pm 251$ grams (1200-2900), mean EFW at second ultrasound was 2805 \pm 341 grams (1430-3950), mean EFW at third ultrasound was $3294 \pm 427$ grams (1900-4750), mean EFW percentile at first ultrasound was $44 \pm 26 \%$, mean EFW percentile at second ultrasound was $44 \pm 27 \%$, mean EFW percentile at third ultrasound was $46 \pm 27 \%$. Mean gestational age at delivery was $39 \pm 1$ weeks (36-42 weeks), mean birth weight was $3422 \pm 423$ grams (1900-4900 grams), mean birth weight percentile was $48 \pm 27$. We used Paired sam- 
ples t-test and Wilcoxon test to understand the effects of patient characteristics on birth weight and estimated fetal weight. Maternal age $(p<0.005)$, maternal weight before pregnancy $(p<0.001)$, maternal weight gain during pregnancy $(p<0.01)$ and gravidity $(p<0.01)$ were statistically significantly associated with the birth weight percentile.

Table 1. Demographic features of the patients

\begin{tabular}{ll}
\hline & Mean \pm SD (range) \\
\hline Maternal age (years) & $30 \pm 4(18-42)$ \\
Maternal height (cm) & $164 \pm 5.8(149-180)$ \\
Gravidity & $1.5 \pm 0.8(0-6)$ \\
Parity & $0.27 \pm 0.5(0-3)$ \\
Maternal weight before pregnancy & $62 \pm 10(40-104)$ \\
Maternal weight at delivery (kg) & $78 \pm 10(54-117)$ \\
Maternal weight gain in pregnancy (kg) & $16 \pm 5(-2$ to+45) \\
Gestational age at first ultrasonography (weeks) & $32 \pm 0.5(30.4-33.6)$ \\
EFW at first ultrasonography (g) & $1954 \pm 251(1200-2900)$ \\
EFW percentile at first ultrasonography & $44 \pm 26(1-100)$ \\
Gestational age at second ultrasonography (weeks) & $36 \pm 0.4(35-36.9)$ \\
EFW at second ultrasonography (g) & $2805 \pm 341(1430-3950)$ \\
EFW percentile at second ultrasonography & $44 \pm 27(1-100)$ \\
Gestational age at third ultrasonography (weeks) & $38.6 \pm 1(36,3-42)$ \\
EFW at third ultrasonography (g) & $3294 \pm 427(1900-4750)$ \\
EFW percentile at third ultrasonography & $46 \pm 27(1-100)$ \\
Gestational age at delivery (weeks) & $39 \pm 1$ (36-42) \\
Birth weight (g) & $3422 \pm 423(1900-4900)$ \\
Birth weight percentile & $48 \pm 27(1-100)$ \\
\hline
\end{tabular}

EFW: Estimated fetal weight, cm: centimeter, kg: kilogram, SD: Standard deviation

Table 2 showed the correlations between the first, second and third ultrasound measurements and the birth weight. All of the measurements correlated with birth weight $(r=0.556, r=0.623, r=0.747$ at first, second and third ultrasound measurements respectively, $p<0.001$ )

Table 2. Correlation between EFW percentile and birth weight percentile

\begin{tabular}{lll}
\hline & \multicolumn{2}{l}{ Birth weight percentile } \\
\cline { 2 - 3 } & $r$ & $p$ \\
\hline First measurement & 0.556 & $0.001^{* *}$ \\
Second measurement & 0.623 & $0.001^{* *}$ \\
Third measurement & 0.747 & $0.001^{\star *}$ \\
\hline
\end{tabular}

r: Pearson correlation coefficient, ${ }^{* *} p<0.01$
Table 3 showed the sensitivity, specificity, positive (PPV) and negative predictive values (NPV) of ultrasound in detecting SGA infants. Sensitivity of ultrasound measurements in detecting SGA infants were $37.5 \%, 50 \%$ and $59.4 \%$ and specificity of ultrasound measurements in detecting SGA infants were $93.8 \%, 92.3 \%$ and $95.7 \%$ respectively at first, second and third ultrasound measurements. PPVs for detection of SGA infants were $39.4 \%, 41 \%$ and $59.4 \%$ and NPVs for detection of SGA infants were $93.4 \%, 94.5 \%$ and $95.7 \%$ respectively for the first, second and third ultrasound measurements. Odds ratio was calculated as 9.13 (4.98-16.73), 12.04(6.77-21.4), 32.27 (17.09-60.89) respectively for the first, second and third ultrasound measurements. 
Table 3. Sensitivity, specificity, positive and negative predictive values (PPV and NPV) of ultrasound in detecting SGA infants

\begin{tabular}{|c|c|c|c|c|c|c|}
\hline \multirow{2}{*}{$\begin{array}{l}\text { Birth weight } \\
\text { percentile }\end{array}$} & \multicolumn{2}{|c|}{ First measurement percentile } & \multicolumn{2}{|c|}{ Second measurement percentile } & \multicolumn{2}{|c|}{ Third measurement percentile } \\
\hline & SGA & Non-SGA & SGA & Non-SGA & SGA & Non-SGA \\
\hline SGA & $24(3.6 \%)$ & $37(5.6 \%)$ & $32(4.8 \%)$ & $46(6.9 \%)$ & $38(5.7 \%)$ & $26(3.9 \%)$ \\
\hline Non-SGA & $40(6.0 \%)$ & $563(84.8 \%)$ & $32(4.8 \%)$ & $554(83.4 \%)$ & $26(3.9 \%)$ & $574(86.4 \%)$ \\
\hline Total & $64(9.6 \%)$ & $600(90.4 \%)$ & $64(9.6 \%)$ & $600(90.4 \%)$ & $64(9.6 \%)$ & $600(90.4 \%)$ \\
\hline OR & \multicolumn{2}{|c|}{$9.13(4.98-16.73)$} & \multicolumn{2}{|c|}{$12.04(6.77-21.40)$} & \multicolumn{2}{|c|}{32.27 (17.09-60.89) } \\
\hline Sensitivity (\%) & \multicolumn{2}{|l|}{37.5} & \multicolumn{2}{|l|}{50} & \multicolumn{2}{|l|}{59.4} \\
\hline Specificity (\%) & \multicolumn{2}{|l|}{93.8} & \multicolumn{2}{|l|}{92.3} & \multicolumn{2}{|l|}{95.7} \\
\hline PPV & \multicolumn{2}{|l|}{39.4} & \multicolumn{2}{|l|}{41} & \multicolumn{2}{|l|}{59.4} \\
\hline NPV & \multicolumn{2}{|l|}{93.4} & \multicolumn{2}{|l|}{94.54} & \multicolumn{2}{|l|}{95.7} \\
\hline Accuracy (\%) & \multicolumn{2}{|l|}{88.4} & \multicolumn{2}{|l|}{88.3} & \multicolumn{2}{|l|}{92.2} \\
\hline
\end{tabular}

SGA: Small for gestational age, OR: Odds oranı, PPV: Positive predictive values, NPV: Negative predictive values

Table 4 showed the sensitivity, specificity, positive and negative predictive values of ultrasound in detecting LGA infants. Sensitivity of ultrasound measurements in detecting LGA infants were $22.9 \%$, $20.8 \%$ and $50 \%$ and specificity of ultrasound measurements in detecting SGA infants were $97 \%, 98 \%$ and $97.7 \%$ respectively at first, second and third ultrasound measurements. PPVs for LGA infants were $37.9 \%, 45.5 \%$ and $63.2 \%$ and NPVs for LGA infants were $94.2 \%, 94.1 \%$ and $96.2 \%$ respectively for the first, second and third ultrasound measurements. Odds ratio was calculated as 9.13 (4.9816.73), 12.04 (6.77-21.4), 32.27 (17.09-60.89) respectively for the first, second and third ultrasound measurements.

Table 4. Sensitivity, specificity, positive and negative predictive values (PPV and NPV) of ultrasound in detecting LGA infants

\begin{tabular}{|c|c|c|c|c|c|c|}
\hline \multirow{2}{*}{$\begin{array}{l}\text { Birth weight } \\
\text { percentile }\end{array}$} & \multicolumn{2}{|c|}{ First measurement percentile } & \multicolumn{2}{|c|}{ Second measurement percentile } & \multicolumn{2}{|c|}{ Third measurement percentile } \\
\hline & LGA & Non-LGA & LGA & Non-LGA & LGA & Non-LGA \\
\hline LGA, n (\%) & $11(1.7)$ & $18(2,7)$ & $10(1.5)$ & $12(1.8)$ & $24(3.6)$ & $14(2.1)$ \\
\hline Non-LGA, n (\%) & $37(5,6)$ & $598(90.1)$ & $38(5.7)$ & $604(91)$ & $24(3.6)$ & $602(90.7)$ \\
\hline Total, $\mathbf{n}(\%)$ & $48(7,2)$ & $616(92.8)$ & $48(7.2)$ & $616(92.8)$ & $48(7.2)$ & $616(92.8)$ \\
\hline OR & \multicolumn{2}{|c|}{$9.87(4.34-22.43)$} & \multicolumn{2}{|c|}{$13.24(5.38-32.61)$} & \multicolumn{2}{|c|}{$43.00(19.87-93.35)$} \\
\hline Sensitivity (\%) & \multicolumn{2}{|l|}{22.9} & \multicolumn{2}{|l|}{20.8} & \multicolumn{2}{|l|}{50} \\
\hline Specificity (\%) & \multicolumn{2}{|l|}{97.1} & \multicolumn{2}{|l|}{98.1} & \multicolumn{2}{|l|}{97.7} \\
\hline$P P V$ & \multicolumn{2}{|l|}{37.9} & \multicolumn{2}{|l|}{45.5} & \multicolumn{2}{|l|}{63.2} \\
\hline$N P V$ & \multicolumn{2}{|l|}{94.2} & \multicolumn{2}{|l|}{94.1} & \multicolumn{2}{|l|}{96.2} \\
\hline Accuracy (\%) & \multicolumn{2}{|l|}{91.7} & \multicolumn{2}{|l|}{92.5} & \multicolumn{2}{|l|}{94.3} \\
\hline
\end{tabular}

LGA: Large for gestational age, PPV: Positive predictive values, NPV: Negative predictive values

On receiver operating curve analysis areas under the curve for SGA were $0.781,0.861$ and 0.911 for the first, second and third ultrasound measurements ( $p<0.001$ for all). On receiver operating curve analysis area under the curve for LGA were 0.752 , 0.791 and 0.881 for the first, second and third ultrasound measurements ( $p<0.001$ for all). 


\section{DISCUSSION}

This study showed that ultrasound examinations done in the third trimester to predict fetal birth weight performed accurately. Ultrasound identified both SGA and LGA infants accurately. Sensitivity of ultrasound was better when a SGA fetus was diagnosed and specificity was better when a LGA fetus was diagnosed at all gestational weeks. Previously Pressman et al announced that ultrasonographic fetal weight estimations predicted birth weight better when performed between 34 and 36.9 weeks of gestation than ultrasonographic fetal weight estimations done at a later gestational age. We compared three serial ultrasonographic measurements and the EFWs obtained at these ultrasonographies correlated with birth weight better when performed after 37 weeks of gestation, just before the delivery. Accuracy of birth weight prediction improved as the term was approached, when more than one US estimation of fetal weight is available depend on the last one said a previous study, ${ }^{12}$ our study confirmed this. We can expect fetal weight estimation prior to labor to be inaccurate due to low position of the head, molding of the bones, distortion of the abdominal circumference and posterior position of the femur. The low sensitivity and high specificity in LGA and SGA groups proved that the ultrasound overestimated LGA and underestimated SGA fetuses. The PPVs for SGA and LGA were low and the NPVs for SGA and LGA were high, the results improved as the gestational age approached term. These results were similar to those reported previously. ${ }^{13-15}$ The PPVs and NPVs were similar at all measurements and high NPVs are important for the exclusion of SGA and LGA fetuses. Although ultrasonographies after 37 weeks predicted birth weight better, identification of SGA fetuses at an earlier gestational week might give us the chance of close monitoring and planning of delivery to reduce perinatal risks. Ultrasound at an earlier gestational age also allows timely identification of placental localization problems.

A previous study by Nelson et al found the ability of early third trimester ultrasonography enough to predict LGA babies of diabetic mothers. ${ }^{16} \mathrm{We}$ excluded patients with GDM and DM because their fetuses are exposed to increased intrauterine nutrients that result in extreme fetal adiposity and growth. ${ }^{17}$ Normal fetuses are expected not to cross the growth curve percentiles, ${ }^{9}$ therefore patients with diseases that were expected to cause growth abnormalities were excluded.

We presented the results of serial ultrasonographies performed by two clinicians; the knowledge of previous ultrasound measurements by the sonographers might have caused bias in the latter measurements.

Amniotic fluid volume may affect the accuracy of the measurements by affecting the image quality and by distorting the abdominal circumference ${ }^{18,19}$ and we did not take it into consideration. Maternal adiposity may also affect the image quality. We did not consider the gender-related differences in fetal weight calculation proposed by previous studies. ${ }^{20,21}$ We did not account the effect of breech presentation on the accuracy of birth weight calculation, a recent study found that the presentation had no effect on EFW when the Hadlock formula was used. ${ }^{22}$ There was no difference in the prediction of the birth weight of the fetus between nullipara and multipara.

Prior knowledge that a fetus is macrosomic may be useful in planning induction of labor after fetal lung maturation to avoid cesarean section. It may also help in counseling parents regarding the complications associated with the vaginal delivery of a macrosomic fetus. To rely on the estimated fetal weight completely may also increase over-management. Previous studies suggested that induction of labor for suspected macrosomia increased the cesarean section rates without improving the perinatal outcome. ${ }^{23,24}$

In conclusion ultrasonographic fetal weight estimations correlate with actual birth weight better when performed in the late third trimester, but ultrasonographic fetal weight estimations in the early third trimester may allow for better follow up and planning of delivery both in SGA and LGA fetuses.

\section{REFERENCES}

1. Heiskanen N, Raatkainen K, Heinonen S. Fetal macrosomia- a continuing obstetric challenge. Biol Neonate 2006;90:98-103.

2. Medchill MT, Peterson CM, Kreinick C, et al. Prediction of estimated fetal weight in extremely low birth weight neonates (500-1000 g). Obstet Gynecol 1991;78:286290.

3. Nahum GG, Stanislaw H. Validation of a birth weight prediction equation based on maternal characteristics. J Reprod Med 2002;47:752-760.

4. Mongelli M, Benzie R. Ultrasound diagnosis of fetal macrosomia: a comparison of weight prediction models using computer simulation. Ultrasound Obstet Gynecol 2005;26:500-503.

5. Chauhan SP, Hendrix NW, Magann EF, et al. Limitations of clinical and sonographic estimates of birth weight: experience with 1034 parturients. Obstet Gynecol 1998;91:72-77 
6. Halaska MG, VIk R, Feldmar P, et al. Predicting term birth weight using ultrasound and maternal characteristics. Eur J Obstet Gynecol Biol 2006;128:231-235

7. Pressman EK, Bienstock JL, Blakemore KJ, et al. Prediction of birth weight by ultrasound in the third trimester. Obstet Gynecol 2000;95:502-506.

8. Krantz C, Hitschold T. Impact and limitations of ultrasound examination immediately before delivery-a prospective evaluation with 1127 pregnant women. Z Geburtshilfe Neonatol 2011;215:69-76.

9. Mongelli M, Gardosi J. Gestation-adjusted projection of estimated fetal weight. Acta Obstet Gynecol Scand 1996;75:28-31.

10. Hadlock FP, Harrist RB, Sharman RS, et al. Estimation of fetal weight with the use of head, body, and femur measurements: a prospective study. Am J Obstet Gynecol 1985;151:333-337.

11. Dudley NJ. A systematic review of the ultrasound estimation of fetal weight. Ultrasound Obstet Gynecol 2005;25:80-89.

12. Larsen T, Greisen G, Petersen S. Prediction of birth weight by ultrasound-estimated fetal weight: a comparison between single and repeated estimates. Eur J Obstet Gynecol Reprod Biol 1995;60:37-40.

13. Ben-Haroush A, Yogev Y, Bar J, et al. Accuracy of sonographic estimated fetal weight in 840 women with different pregnancy complications prior to induction of labor. Ultrasound Obstet Gynecol 2004;23:172-176.

14. Colman A, Maharaj D, Hutton J, et al. Reliability of ultrasound estimation of fetal weight in term singleton pregnancies. N Z Med J 20068;119:2146-2149.

15. Ben-Haroush A, Yogev $Y$, Hod M, et al. Predictive value of a single early fetal weight estimete in normal pregnancies. Eur J Obstet Gynecol Biol 2007;130:187192.
16. Nelson L, Wharton B, Grobman WA. Prediction of large for gestational age birth weights in diabetic mothers based on early third trimester sonography. J Ultrasound Med 2011;30:1625-1628.

17. Kehl RJ, Krew MA, Thomas A, Catalano PM. Fetal growth and body composition in infants of women with diabetes mellitus during pregnancy $\mathrm{J}$ Matern Fetal Med 1996;5:273-280.

18. Blann DW, Prien SD. Estimation of fetal weight before and after amniotomy in the laboring gravid woman. Am J Obstet Gynecol 2000 ;182:1117-1120.

19. Townsend RR, Filly RA, Callen PW, et al. Factors affecting prenatal sonographic estimation of weight in extremely low birthweight infants. J Ultrasound Med 1988; 7:183-187.

20.Schild RL, Sachs C, Fimmers R, et al. Sex-specific fetal weight prediction by ultrasound. Ultrasound Obstet Gynecol 2004;23:30-35.

21. Schwarzler P, Bland JM, Holden D, et al. Sex-specific antenatal reference growth charts for uncomplicated singleton pregnancies at 15-40 weeks of gestation. Ultrasound Obstet Gynecol 2004;23:23-29.

22. McNamara JM, Odibo AO, Macones GA, Cahill AG. The effect of breech presentation on the accuracy of estimated fetal weight. Am J Perinat 2012;29:353360.

23. Sanchez- Ramos L, Bernstein S, Kaunitz AM. Expectant management versus labor induction for suspected fetal macrosomia: a systematic review. Obstet Gynecol 2002;100:997-1002.

24. Weiner Z, Ben-Shlomo I, Beck-Fruchter R, et al. Clinical and ultrasonographic weight estimation in large for gestational age fetus. Eur J Obstet Reprod Biol 2002;105:20-24. 